\title{
Algumas Considerações a Respeito do que as Crianças Sabem sobre a Morfologia Derivacional
}

\author{
Márcia Maria Peruzzi Elia da Mota \\ Universidade Federal de Juiz de Fora
}

\begin{abstract}
RESUMO
Estudos realizados em língua inglesa mostram que a habilidade de refletir sobre os morfemas que compõem as palavras está associada ao sucesso no reconhecimento e compreensão de palavras, na leitura, e na escrita. No português a maioria dos estudos nesta área focou no desenvolvimento da morfologia flexional. Considera-se que a morfologia derivacional se desenvolve depois de alguns anos de escolarização. Neste estudo, investigamos o desenvolvimento da morfologia derivacional no português do Brasil, em uma amostra de 51 crianças, sendo 27 alunas da $1^{\mathrm{a}}$ série e 24 da $2^{\mathrm{a}}$ série do ensino fundamental de uma escola pública, situada na região urbana de Juiz de Fora, Minas Gerais. Seis tarefas de consciência morfológica foram aplicadas, e o nível de acerto em cada tarefa computado. Os resultados sugerem que a habilidade de refletir sobre os morfemas está presente desde cedo, ainda que de forma rudimentar, e que continua a se desenvolver com a escolarização.
\end{abstract}

Palavras-chave: consciência metalingüística; consciência morfológica; desenvolvimento cognitivo.

\begin{abstract}
Some Considerations About Children's Knowledge of Derivational Morphology

Studies carried out in English orthography show that the ability to reflect upon the word's morphemes is related to the success in recognizing words, reading comprehension and spelling. The majority of the studies carried out in Portuguese in this area focused in the development of flexional morphology. It is considered that the derivational morphology develops after some years of schooling. In this study we investigated the development of the derivational morphology in Brazilian Portuguese language, with a sample of 51 children, of which 27 were from $1^{\text {st }}$ grade and 24 from $2^{\text {nd }}$ grade, all drawn from a federal school from the urban area of Juiz de Fora, Minas Gerais. Six morphological awareness tasks were used. The number of correct responses in each task computed. The results suggest that the ability to reflect upon the morphemes is present at an early stage, even if in a rudimentary form and that it continues to develop with schooling.
\end{abstract}

Keywords: metalinguistic awareness; morphological awareness; cognitive development.

A habilidade se refletir sobre os morfemas que compõem as palavras é chamada de consciência morfológica (Carlisle, 1995). Morfemas são as menores unidades lingüísticas que tem significado próprio. Em anos recentes, a atenção de muitos pesquisadores se voltou para o papel que o processamento morfológico tem no processo de alfabetização. Talvez os trabalhos mais citados nesta área sejam os de Joanne Carlisle, que mostrou que a habilidade de refletir sobre os morfemas que compõem as palavras estava associada ao desempenho na leitura de palavras isoladas e a compreensão de leitura (Carlisle, 1995, 2000; Carlisle \& Fleming, 2003), e também ao desempenho da escrita (Carlisle, 1988, 1996).
A escrita combina dois tipos de princípios: o princípio fonográfico e o semiográfico. O primeiro envolve estabelecer como unidades gráficas, os grafemas ou letras, correspondem aos sons que compõem a fala, ao nível dos fonemas ou sílabas. O segundo princípio, o semiográfico, envolve estabelecer como os grafemas representam significados (Marec-Breton \& Gombert, 2004). O processamento morfológico está mais fortemente associado ao princípio semiográfico, ao passo que o processamento fonológico está mais fortemente associado ao princípio fonográfico.

Considerando estes dois princípios, Mann (2000) ressalta que o processamento morfológico pode ser importante para leitura porque a escrita pode ser anali- 
sada em vários níveis. Normalmente estudos sobre o processamento da escrita focam no nível fonológico, mas a morfologia pode ser um importante aspecto do processamento da escrita. A ortografia de muitas palavras depende da morfologia. Palavras como "laranjeira", que têm ortografia ambígua, podem ser escritas de forma correta se soubermos sua origem: "laranja". Os significados delas podem ser igualmente inferidos na leitura, se soubermos o significado da palavra que as originou.

Uma segunda razão pela qual o processamento morfológico pode ser importante seria mais específica à natureza da ortografia sendo estudada. A argumentação principal para explicar a relação encontrada entre o processamento morfológico e a alfabetização, vem de pesquisas realizadas em falantes do inglês, língua nativa de Mann, e diz respeito à natureza da ortografia inglesa.

De acordo com Byrne e Fielding-Barnsley (1989), um dos fatores que envolvem a compreensão do princípio alfabético diz respeito ao conhecimento das regras de correspondência entre grafemas e fonemas, mas as línguas alfabéticas variam quando ao grau de correspondência entre as letras e os sons da fala. No inglês essas relações são mais opacas do que em ortografias como o finlandês, o português ou o espanhol. Muitas das irregularidades encontradas no inglês podem ser explicadas pela estrutura morfológica das palavras (Chomsky \& Halle, 1968; Sterling, 1991). Por exemplo, no inglês a palavra 'heal' que rima com 'il' e a palavra 'health' que rima com 'elf' têm a mesma origem semântica, por isso são escritas da mesma forma, embora sejam pronunciadas de forma diferente.

Nas línguas com ortografias mais regulares, o processamento morfológico pode não contribuir de forma significativa para aquisição e processamento da língua escrita, porque a maioria das palavras pode ser escrita aplicando-se o princípio alfabético. Lehtonen e Bryant (2005) ressaltam que embora este seja um argumento válido, a hipótese de que a consciência morfológica contribui para alfabetização nestas ortografias regulares também é pertinente. Os autores argumentam que esta é uma questão teórica que precisa ser mais bem investigada. Assim, é possível que o papel da consciência morfológica seja diferente em diferentes ortografias.

Mann (2000) supõe que as línguas alfabéticas mais regulares podem ser mais dependentes da estrutura fonológica das palavras do que da estrutura morfológica. Entretanto, estudos feitos em diferentes ortogra- fias vêm confirmando que há uma associação entre processamento morfológico e aquisição da língua escrita (Colé, Marec-Breton, Royer \& Gombert, 2003; Lehtonen \& Bryant, 2005; Plaza \& Cohen, 2004; Rego \& Buarque, 1997; Queiroga, Lins \& Pereira, 2006). Embora o processamento morfológico não contribua com o mesmo peso do processamento fonológico, esta contribuição parece ser independente de outras habilidades metalingüísticas (Deacon \& Kirby, 2004; Nagy, Berninger \& Abbot, 2006; Plaza \& Cohen, 2004).

Existem duas grandes classes de morfemas: as raízes e os afixos. A raiz pode ser definida como núcleo mínimo de uma construção morfológica. Os afixos podem ser de dois tipos: prefixos, afixos adicionados antes da raiz, ou sufixos, afixos adicionados depois da raiz. Os morfemas também podem ser classificados como flexões ou derivações. As flexões são sufixos que determinam o gênero e o número nos substantivos e adjetivos, e nos verbos constituem os sufixos temáticos, modo-temporais e número-pessoais (ver Laroca, 2005, para uma revisão). As derivações, por sua vez, podem ser prefixos (ex., "refazer") ou sufixos (ex., "leiteiro"). As flexões têm um caráter morfossintático e possuem uma estabilidade semântica, ao passo que as derivações tratam da estrutura das palavras, neste caso pode haver extensões do sentido destas palavras (Laroca, 2005).

Pesquisas têm demonstrado que as crianças reagem de forma diferente à morfologia derivacional e a flexional (Deacon \& Bryant, 2005). Deacon e Bryant deram a crianças de cinco a oito anos de idade um teste de escrita, no qual as crianças tinham que escrever palavras com um morfema e palavras com dois morfemas. Metade das palavras de dois morfemas era de palavras derivadas e a outra metade eram palavras flexionadas. As palavras tinham o mesmo som final, por exemplo, a palavra notion (com um morfema) e a palavra connection (com dois morfemas). Os autores predisseram que se as crianças processam a morfologia da língua, elas teriam uma facilidade maior em escrever o som final das palavras quando eles eram morfemas, do que quando não eram. Já que o som final das palavras era o mesmo, qualquer diferença nos resultados só poderia ser atribuída ao processamento morfológico da palavra. Os resultados deste estudo mostraram que as crianças escreviam mais corretamente os sons finais das palavras quando eram morfemas do que quando não eram, mas a análise do tipo de morfema escrito mostrou que este resultado era verdadeiro apenas para as flexões. Os autores con- 
cluíram que a diferença encontrada na escrita dos dois tipos de morfemas possivelmente ocorria porque na morfologia derivacional há uma mudança na classe gramatical das palavras morfologicamente complexas, o que não ocorre com a morfologia flexional. Assim, seria mais fácil para as crianças entender as relações morfêmicas nas flexões do que nas derivações.

No caso da morfologia derivacional, como discutido acima, não há regras claras de como formar as palavras, no entanto, conhecer a relação entre a raiz e a palavra derivada pode ajudar o leitor a compreender o significado da palavra e saber como pronunciá-la, e ao escritor decidir sobre grafias ambíguas. Assim, o desenvolvimento da consciência morfológica pode ocorrer de forma diferente para morfologia flexional e para a morfologia derivacional.

Estudando a morfologia flexional Nunes, Bryant e Bindman (1997) argumentam que o processamento morfológico ocorre tardiamente no desenvolvimento. Através de um estudo longitudinal os autores mostraram que as crianças parecem passar por uma seqüência de estágios no seu entendimento de como as palavras morfologicamente complexas são formadas. Os autores estudaram a aquisição da escrita de morfemas como o "ed" no inglês, e argumentam que antes que as crianças possam escrever a grafia de palavras morfologicamente complexas, que fogem aos padrões de correspondência entre letra e som, elas precisam ter entendido o princípio alfabético. Os resultados do estudo de Nunes e cols. (1997) estão de acordo com os principais modelos de desenvolvimento da escrita que trabalham com a idéia de desenvolvimento em estágios (Marsh, Friedman, Welsh \& Desberg, 1980; Frith, 1985). No entanto, é possível que o desenvolvimento da escrita possa não ocorrer em estágios, e que também não seja necessário que as crianças tenham adquirido o princípio alfabético, antes de usar informações morfológicas. Estudos posteriores ao de Nunes e col. (1997) têm mostrado que as crianças se beneficiam da morfologia da língua desde cedo no processo de alfabetização (Colé, Marec-Breton, Royer \& Gombert, 2003; Deacon \& Kirby, 2004). No que diz respeito à morfologia derivacional o seu desenvolvimento é apresentado como ocorrendo ainda mais tardiamente, do que no caso da morfologia flexional (Deacon \& Bryant, 2005).

Os estudos que estudaram o desenvolvimento da morfologia no português do Brasil focam no desenvolvimento da morfologia flexional e sua relação com o desenvolvimento ortográfico. Em uma série de estudos investigou a relação entre o processamento mor- fológico e a escrita. Mota (1996) mostrou que a partir da segunda série as crianças são capazes de utilizar regras gramaticais para decidir a grafia de palavras flexionadas. Mota, Moussatché, Castro, Moura e Ribeiro (2000) mostraram que adolescentes com baixa escolaridade processam os morfemas das palavras na escrita, e em um outro estudo Mota e cols. (2002) observaram que as crianças de primeira série com os melhores escores nos testes de consciência morfológica eram também as crianças que escreviam melhor pseudopalavras com ortografia ambígua (ex., "muge"-“mugidor").

Meireles e Correa (2005) examinaram o desenvolvimento ortográfico em crianças no Ensino Fundamental. Crianças da $2^{\mathrm{a}}$ e $4^{\mathrm{a}}$ séries realizaram um ditado de palavras de baixa freqüência de ocorrência que incluía regras de natureza morfossintática (sufixos

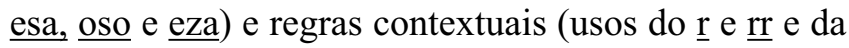
nasalização antes de consoantes). Os resultados mostraram que como no estudo de Mota (1996) as crianças apresentam um desenvolvimento na aplicação de regras morfossintáticas na escrita. Estudando a relação entre ortografia e morfo-sintaxe, Rego e Buarque (1997) observaram que a consciência morfossintática das crianças contribuiu para o desempenho na escrita de palavras morfologicamente complexas.

Em outro estudo que investigou a relação entre consciência morfossintática e desempenho ortográfico de crianças de $2^{\mathrm{a}}$ e $4^{\mathrm{a}}$ séries do ensino fundamental, Queiroga, Lins, e Pereira (2006) avaliaram a escrita das crianças através de ditados de palavras e pseudopalavras, e para avaliar a consciência morfo-sintática utilizaram a tarefa de analogia gramatical. Os resultados deste estudo mostraram uma evolução entre as séries na escrita de palavras e pseudopalavras e na explicitação do conhecimento morfossintático. Encontrou-se também um efeito facilitador do conhecimento morfossintático para a escrita.

Como levantamos anteriormente, menos se sabe a respeito do desenvolvimento do processamento da morfologia derivacional e sua relação com a alfabetização no português. Para investigar esta questão Mota, Annibal e Lima (no prelo) realizaram um estudo com crianças falantes do português. O resultado deste estudo mostrou que tarefas de consciência morfológica avaliando a morfologia derivacional, correlacionaram de forma positiva e significativa com o desempenho na leitura e escrita, e que em alguns casos esta contribuição foi independente da consciência fonológica. No entanto, o estudo de Mota, Annibal e Lima (no prelo) não explorou o desenvolvimento da consciência morfológica no português. Este estudo 
pretende explorar o desenvolvimento do processamento da morfologia derivacional no português. Comparando a performance das crianças de primeira e segunda série em seis tarefas de consciência morfológica. Desta forma, podemos mostrar se as crianças de primeira série são capazes de processar a morfologia da língua. Podemos também investigar o efeito da escolarização no desenvolvimento da morfologia derivacional.

\section{MÉTODO}

\section{Participantes}

A amostra do estudo foi constituída por 51 crianças, sendo 27 alunas da $1^{\mathrm{a}}$ série e 24 da $2^{\mathrm{a}}$ série, todas do ensino fundamental de uma escola pública, situada na região urbana de Juiz de Fora. Dessas turmas três outras crianças não iniciaram no estudo (uma mudou de escola e as outras duas não quiseram participar da pesquisa). A média de idade das crianças de $1^{\mathrm{a}}$ série foi de 91.1 meses (dp 4.8) e a da segunda série 103,9 meses (dp. 5,53). A participação no estudo dependeu da autorização do responsável através do Termo de Consentimento Livre e Esclarecido.

\section{Instrumentos}

Tarefas de consciência morfológica:

A) Tarefa de Decisão Morfo-semântica (Besse, Vidigal de Paula \& Gombert, comunicação pessoal, setembro de 2005)

Nesta tarefa a criança tinha que decidir se uma palavra era construída da mesma forma que as outras. A explicação dada à criança era a seguinte: "em português há palavras que são da mesma família, como, por exemplo, "descobrir" e "cobrir", ou seja, "descobrir" vem de "cobrir". Acrescenta-se uma pequena coisa no início para fazer uma outra palavra. Outro exemplo é o caso de "desfazer" e "fazer", onde acrescenta o "des" no início de "fazer". Porém, há palavras que também se iniciam por "des", mas não vem de outra palavra como é o caso de "deslizar" que não vem de "lizar". Após a explicação fazia-se um exemplo com a criança: "qual a palavrinha que é feita da mesma maneira que "descobrir" é "deslizar" ou "desfazer?". Havendo a criança respondido corretamente, iniciavase a tarefa; do contrário, dava-se a forma correta explicando a razão. A lista de palavras consistia de 12 grupos de três palavras envolvendo prefixos e 12 grupos de palavra envolvendo sufixos (ver Apêndice).
B) Tarefas de Decisão Morfo-semântica - raiz (variação de Besse, Vidigal de Paula \& Gombert, comunicação pessoal, setembro de 2005).

A tarefa de Besse, Vidigal de Paula e Gombert foi inicialmente delineada para crianças mais velhas do que as que participaram desse estudo. Com o objetivo de simplificar a tarefa original uma variação da mesma foi criada investigando o conhecimento da raiz das palavras. Utilizamos o termo variação e não adaptação, pois se tratou de uma modificação da tarefa e não uma adaptação da mesma para o contexto deste estudo. Nesta tarefa a criança tinha que decidir qual palavra era da mesma família que a palavra alvo. Assim se explicava o seguinte: "algumas palavrinhas são da mesma família do que outras. Por exemplo, a palavra "conta" e a palavra "reconta" são da mesma família. Já a palavra "bola" e "rebola" não são da mesma família. Eu vou falar para você uma palavra e depois vou falar mais outras duas e você vai me dizer qual das duas é da mesma família da primeira". Por fim se fazia um exemplo junto com a criança: "a palavra "gela" é da mesma família que "congela" ou "conversa"?. Caso a criança errasse, explicava-se a forma correta, e se acertasse iniciava-se a tarefa.

Os pares de palavra foram pareadas pelo número de letras e a freqüência de ocorrência na escrita (Pinheiro, 1996; tabela para primeira série). Como não há índices de familiaridade para o português as palavras foram pareadas por freqüência para garantir minimamente um equilíbrio na familiaridade das palavras. A lista de palavras consistia de dez grupos de três palavras envolvendo prefixos e dez grupos de palavra envolvendo sufixos (ver Apêndice).

C) Tarefa de Associação Morfo-Semântica (Nagy, Berninger \& Abbot, 2006).

Essa tarefa foi adaptada do inglês. As palavras foram escolhidas para atender as características do português. Nessa tarefa a criança tinha que decidir se duas palavras eram da mesma família ou de famílias diferentes. Assim, dava-se a explicação: "a palavra "bola" e a palavra "bolinha" são da mesma família. Já a palavra "bolo" e "bolinha" não". Depois um exemplo era feito junto com a criança: "a palavra bola é da mesma família que boleiro?". Respondendo de maneira exata, começava a atividade e caso a resposta estivesse incorreta, dizia-se a palavra correta e apresentava-se a explicação do exemplo (ver Apêndice). Dez pares de palavras foram criados no português, cinco pares pertenciam à mesma família e cinco eram de famílias diferentes. Todas as palavras partilhavam do mesmo 
som inicial, de maneira que diferenças no desempenho não poderiam ser atribuídas à semelhança fonológica, mas ao conhecimento da relação morfo-semântica das palavras.

D) Tarefa de Analogia Gramatical (adaptada de Nunes, Bindman \& Bradley, 1997)

Adaptamos a tarefa inicial de Nunes, Bindman \& Bradley (1997) para focar mais especificamente na morfologia derivacional do português. Nesta tarefa a criança tinha que produzir uma palavra morfologicamente complexa a partir de uma palavra alvo, aplicando a mesma relação de derivação de um par previamente dado, como por exemplo: "pedra-pedreiro; leite- ?" e assim sucessivamente com os outros pares. Dez itens foram criados (ver Apêndice).

\section{Testes padronizados:}

Teste de Desempenho Escolar-TDE (Stein, 1994) Os itens de leitura de palavras isoladas e escrita do TDE foram aplicados para avaliar o desempenho na leitura e escrita das crianças.

Escala de Inteligência Wechsler para criançasWISC III (Weschler, 1991) - Os subtestes de Vocabulário, Compreensão e Dígitos foram aplicados. Os escores ponderados foram utilizados. Este teste foi aplicado para controlarmos a influência do desenvolvimento cognitivo na aquisição da leitura e escrita.

\section{Procedimento}

As crianças foram avaliadas individualmente em três sessões de 20 a 30 minutos. Na primeira foram realizados os testes de consciência morfológica e os testes de consciência fonológica (não discutido aqui). $\mathrm{Na}$ segunda sessão foram aplicados três subtestes do WISC (Vocabulário, Compreensão e Dígitos) e na última sessão foram aplicados os dois subtestes do Teste de Desempenho Escolar.

\section{RESULTADOS}

Análise da Performance nas Diferentes Tarefas

\section{A) Tarefas de Decisão Morfo-Semântica}

As tarefas de decisão morfo-semântica consistiam na escolha de uma palavra entre duas escolhas possíveis. As crianças tinham $50 \%$ de chance de acertar a tarefa se estivessem fazendo julgamentos sobre a morfologia da língua apenas "adivinhando" as respostas. $\mathrm{O}$ número de respostas corretas foi computado. A Tabela 1 mostra a média e a porcentagem de acertos para cada uma das tarefas aplicadas.

\section{TABELA 1}

Porcentagem, Média e o Desvio Padrão (d.p.) para o Número de Respostas Corretas para cada Tarefa de Consciência Morfológica por Série

\begin{tabular}{|c|c|c|c|}
\hline Tarefa & $\begin{array}{l}1^{\text {a }} \text { série (\%) } \\
\text { média (d.p.) }\end{array}$ & $\begin{array}{l}2^{\text {a }} \text { Série }(\%) \\
\text { média (d.p.) }\end{array}$ & Número de itens \\
\hline $\begin{array}{l}\text { Decisão Morfo-Semântica - } \\
\text { raiz (prefixo) }\end{array}$ & $\begin{array}{c}95 \% \\
9,5(0,8)\end{array}$ & $\begin{array}{c}95 \% \\
9,5(0,9)\end{array}$ & 10 \\
\hline $\begin{array}{l}\text { Decisão Morfo-Semâtica - } \\
\text { raiz (sufixo) }\end{array}$ & $\begin{array}{c}95 \% \\
9,5(0,7)\end{array}$ & $\begin{array}{c}96 \% \\
9,6(1,0)\end{array}$ & 10 \\
\hline $\begin{array}{l}\text { Decisão Morfo-Semântica } \\
\text { (prefixo) }\end{array}$ & $\begin{array}{c}54 \% \\
6,5(1,5)\end{array}$ & $\begin{array}{c}58 \% \\
7,0(1,4)\end{array}$ & 12 \\
\hline Decisão Morfo-Semâtica (sufixo) & $\begin{array}{c}49 \% \\
5,9(1,2)\end{array}$ & $\begin{array}{c}50 \% \\
6,0(2,4)\end{array}$ & 12 \\
\hline Analogia Gramatical & $\begin{array}{c}52 \% \\
5,2(2,0)\end{array}$ & $\begin{array}{c}71 \% \\
7,1(1,2)\end{array}$ & 10 \\
\hline $\begin{array}{l}\text { Tarefa de Associação } \\
\text { Morfo-Semântica }\end{array}$ & $\begin{array}{c}63 \% \\
6,3(1,4)\end{array}$ & $\begin{array}{c}75 \% \\
7,5(1,6)\end{array}$ & 10 \\
\hline
\end{tabular}

Com exceção da tarefa de Decisão Morfo-Semâtica (sufixo) de Besse, Vidigal de Paula e Gombert (comunicação pessoal, setembro de 2005), as crianças tiveram níveis de acerto superiores a $50 \%$ nas tarefas de consciência morfológica. Estes resultados foram encontrados tanto para as crianças de primeira série, como para as crianças de segunda série. 


\section{B) Tarefa de Associação Morfo-Semântica}

Julgamentos realizados na tarefa de decisão morfosemântica baseada na raiz das palavras, podem ter sido afetados pela estrutura fonológica das palavras. A palavra 'Pinheiro' mantém a estrutura fonológica de 'Pinho'. Portanto a Tarefa de Associação MorfoSemântica foi incluída no estudo como controle. Nesta tarefa a criança tinha que decidir se um par de palavras vinha da mesma família ou eram de famílias diferentes. O nível de acertos por chance aqui também era de $50 \%$. No entanto, uma consideração metodológica precisa ser feita neste caso. Gombert (1992) argumenta que em tarefas de julgamento de gramaticalidade há uma tendência das crianças aceitarem todos os itens como corretos. Neste caso, a criança teria uma média de acerto de $50 \%$ no teste. Gombert sugere então que se adote um critério mais conservador na análise do nível de chance destes testes. $\mathrm{O}$ autor sugere que se adote como critério um nível de acerto de $75 \%$. Este número envolveria acertar todos os pares de mesma família (50\%) e pelo menos $50 \%$ dos pares de famílias diferentes (25\%). Não há ainda, na literatura, evidências de uma tendência a aceitar pares de palavras como fossem da mesma família no caso da morfologia derivacional, mas discutiremos os resultados adotando os dois critérios.

Se adotarmos o critério menos conservador tanto as crianças de primeira série $(63 \%)$ quanto às crianças de segunda-série $(75 \%)$ obtiveram níveis de acerto superiores a $50 \%$ nesta tarefa. Entretanto, adotando-se o critério mais conservador, encontramos que apenas as crianças de segunda série foram capazes de fazer julgamentos morfológicos quando a estrutura fonológica das palavras foi controlada.

\section{C) Analogia Gramatical}

$\mathrm{Na}$ tarefa de analogia gramatical as crianças tinham que produzir uma resposta correta ao invés de apenas julgá-la, o que acrescenta uma dificuldade a tarefa, e exige um grau maior de controle cognitivo por parte da criança. Nesta tarefa as diferenças entre as crianças de primeira e segunda-série foram mais marcantes. No entanto, mesmo as crianças de primeira série tiveram performance superior a 50\% (52\%).

\section{Comparações entre Séries}

Para investigar se houve um efeito da escolarização sobre o desempenho da consciência morfológica, testes não paramétricos Mann-Whitney foram realizados nos dados sobre o número de acerto em cada teste de consciência morfológica. As crianças de primeira série tiverem desempenhos estatisticamente inferiores em três dos seis testes de consciência morfológica: a tarefa de decisão morfo-semântica envolvendo o sufixo e a raiz das palavras $(\mathbf{Z}=-1,98 ; \mathbf{p}<0,047)$, tarefa de associação morfo-semântica $(\mathbf{Z}=-2,48 ; \mathbf{p}<0,013)$ e no teste de analogia gramatical $(\mathbf{Z}=-3,53$; $\mathbf{p}<0,001)$.

\section{DISCUSSÃO}

De um modo geral os resultados indicam que as crianças desde a primeira série são capazes de refletir sobre os aspectos morfológicos das palavras. No entanto, os resultados demonstram também que esta habilidade ainda está em desenvolvimento neste momento. Em três das tarefas, as crianças de segunda série tiveram desempenhos estatisticamente superiores aos das crianças de primeira série, indicando uma evolução na capacidade de processamento morfológico.

As crianças de primeira série foram capazes de realizar julgamentos sobre a relação morfológica das palavras com níveis de acerto superiores a $50 \% \mathrm{em}$ quase todas as tarefas. Estes julgamentos parecem ser mais fáceis quando a estrutura fonológica da palavra é conservada. Resultados semelhantes foram obtidos por Carlisle, Stone \& Katz (2001), que mostraram que pares de palavras morfologicamente relacionadas com relações fonológicas simples ('four' e 'fourth') são mais fáceis de reconhecer, do que pares com estrutura fonológica complexa ('five' e 'fith').

Resultados como esses, no entanto, são difíceis de interpretar. Não temos como separar o conhecimento da estrutura fonológica das palavras, do conhecimento da estrutura morfológica. Quando controles são efetuados para controlar o efeito facilitador do processamento fonológico, como no caso da tarefa de associação morfo-semântica, as crianças de primeira série apresentam desempenho abaixo do critério conservador que adotamos. No entanto, cabe ressaltar que ainda assim, o nível de acerto para essas crianças foi acima do nível de chance.

Diferentes tarefas exigem diferentes níveis de controle sobre a morfologia da língua (ver Gombert, 2003; Mota, 1996; Nunes \& Bryant, 2006; para uma discussão sobre níveis de controle metalingüístico). Tarefas que exigiam decisões mais explícitas sobre a morfologia da língua, como a tarefa de Besse, Vidigal de Paula \& Gombert (comunicação pessoal, setembro de 2005), que exigia que a criança entendesse o significado do afixo nas diferentes palavras, levaram a baixos índices de desempenho, por parte das crianças 
mais novas. No entanto, estes resultados sozinhos não podem ser considerados como evidência de que as crianças pequenas não processam a morfologia da língua. $\mathrm{Na}$ tarefa de analogia gramatical, que envolve a produção (e não apenas o julgamento da relação morfológica das palavras, o que requer um grau maior de controle cognitivo), as crianças de primeira série tiveram um índice de acerto de $52 \%$. Também na tarefa de associação morfo-semântica foi superior ao nível de chance $(63 \%)$.

Estes resultados parecem indicar que como no caso do processamento da consciência sintática há uma progressão no nível de processamento da morfologia de um nível mais implícito para um mais explícito. Este ponto é levantado por Gombert em uma série de trabalhos publicados (Gombert, 1992, 2003; Demont $\&$ Gombert, 2004). Gombert e seus colegas argumentam que algum nível de habilidade metalingüística é necessário para que se possa aprender a ler e escrever (nível implícito ou epilingüístico), mas a habilidade verdadeiramente metalingüística (nível explícito) depende das aprendizagens escolares.

Embora a definição de processamento implícito e explícito em psicologia cognitiva envolva muita controvérsia, nossos resultados indicam que a habilidade de refletir sobre os morfemas que compõe as palavras se desenvolve ao longo dos primeiros anos de escolarização. Estes resultados indicam também, que ao contrário do que prevê o modelo de Marsh e cols (1980), Frith (1985), Nunes e cols. (1997), desde a primeira série esta habilidade está presente, ainda que de forma rudimentar.

Uma última consideração a respeito das implicações pedagógicas destas descobertas: Nunes \& Bryant (2006), em livro publicado recentemente, propõem que o ensino das relações morfêmicas entre as palavras ajuda na alfabetização. Os autores ressaltam, no entanto, que a tradução dos resultados de pesquisa para o contexto escolar precisa ser feito cuidadosamente. Não temos ainda um corpo grande de evidências empíricas a respeito da importância da consciência morfológica para alfabetização de crianças no ensino regular. De fato, uma revisão bibliográfica realizada em dois bancos de dados utilizados por psicólogos (Web of Science e Psycinfo) resultou no levantamento de apenas três estudos que investigaram o papel da morfologia nas dificuldades de aprendizagem de crianças sem necessidades especiais. Esta revisão mostrou que mais pesquisas são necessárias, sobretudo aquelas que envolvam trabalhos de intervenção tanto no contexto do laboratório, quanto no contexto escolar para podermos avaliar o benefício do desenvolvimento do processamento morfológico para aprendizagem da leitura e escrita, e que essa é uma lacuna que precisa ser preenchida também para a realidade educacional brasileira.

\section{REFERÊNCIAS}

Byrne, B., \& Fielding-Barnsley, R. (1989). Phonemic awareness and letter knowledge in the child's acquisition of the alphabetic principle. Journal of Educational Psychology, 81(3), 313-321.

Carlisle, J. (1988). Knowledge of derivational morphology and spelling ability in fourth, six, and eight graders. Applied Psycholinguistics, 9, 247-266.

Carlisle, J. (1995). Morphological awareness and early reading achievement. Em L. Feldman (Org.) Morphological aspects of language processing (pp. 189-211). Hillsdale: Lawrence Erlbaum Associates.

Carlisle, J. (1996). An exploratory study of morphological errors in children's written stories. Reading and Writing: An Interdisciplinary Journal, 8, 61-72.

Carlisle, J. (2000). Awareness of the structure and meaning of morphologically complex words: Impact on reading. Reading and Writing: An Interdisciplinary Journal, 12, 169-190.

Carlisle, J., Stone, C., \& Katz, L. (2001). The effects of phonological transparency on reading derived words. Annals of Dyslexia, 51, 249-274.

Carlisle, J., \& Fleming, J. (2003). Lexical processing of morphologically complex words in the elementary years). Scientific Studies of Reading, 7(3), 239-253.

Chomsky, N., \& Halle, M. (1968). The sound patterns of English. New York: Harper \& Row.

Colé, P., Marec-Breton, N., Royer, C., \& Gombert, J. E. (2003). Morphologie des mots et apprentissage de la lecture. Rééducation Orthophonique, 213, 57-60.

Deacon, S., \& Bryant, P. (2005). What young children do and do not know about the spelling of inflections and derivations. Developmental Science, 8(6), 583-594.

Deacon, S., \& Kirby, J. (2004). Morphological awareness: Just "more phonological"? The roles of morphological and phonological awareness in reading development. Applied Psycholinguistics, 25, 223-238.

Demont, E., \& Gombert, J. E. (2004). Lápprentissage de la lecture: Évolution des procédures et apprentissage implicite. Enfance, 3, 245-257.

Frith, U. (1985). Beneath the surface of developmetal dislexia. Em K. Patterson, M. Coltheart, J. Marshal (Orgs.), Surface dislexia (pp. 301-330). London: Lawrence Erlbaum Associates.

Gombert, J. E. (1992). Metalinguistic development. Hertfordshire: Harverster Wheatsheaf.

Gombert, J. (2003). Atividades metalingüística e aquisição da leitura. Em M. R. Maluf (Org), Metalinguagem e aquisição da escrita (pp. 19-64). São Paulo: Casa do Psicólogo.

Laroca, M. (2005). Manual de morfologia do português. Campinas: Pontes; Juiz de Fora: Editora da UFJF. 
Lehtonen, A., \& Bryant, P. (2005). Active players or just passive bystanders? The role of morphemes in spelling development in a transparent orthography. Applied Psycholinguistics, 26(2), 137-155.

Mann, V. (2000). Introduction to special issue on morphology and the acquisition of alphabetic writing systems. Reading and Writing: an Interdisciplinary Journal, 12, 143-147.

Marec-Breton, N., \& Gombert, J. (2004). A dimensão morfológica nos principais modelos de aprendizagem da leitura. Em M. R. Maluf (Org.), Psicologia educacional: Questões contemporâneas (pp. 105-122). São Paulo: Casa do Psicólogo.

Marsh, G., Friedman, M., Welsh, V., \& Desberg, P. (1980). The development of strategies in spelling. Em U. Frith (Org.), Cognitive processes in spelling (pp. 339-353). London Academic Press.

Meireles, E., \& Correa, J. (2005). Regras contextuais e morfossintáticas na aquisição da ortografia da língua portuguesa por criança. Psicologia: Teoria e Pesquisa, 21(1), 77-84.

Mota, M. (1996). Children's role of grammatical rules in spelling. Tese de doutorado não publicada, departamento de Psicologia Experimental, Universidade de Oxford, Inglaterra.

Mota, M., Moussatché, A. H., Castro, C., Moura, M. L. S., \& Ribeiro, T. (2000). Erros de escrita no contexto: Uma análise dentro da abordagem da teoria do processamento da informação. Revista Psicologia: Reflexão e Crítica, 13(1), 1-6.

Mota, M, Andrade, C., Henrique, D, Macedo, S., Atalaia, K., Stephan, F., \& Ferreira, D. (2002). Conciência sintática e desenvolvimento ortográfico. Em Encontros Psicopedagógicos Anais do IV Seminário de Psicopedagogia da UERJ - v. 1 (pp. 35-39). Rio de Janeiro: UERJ.

Mota, M., Annibal, L., \& Lima, S. (no prelo). A morfologia derivacional contribui para a leitura e escrita no português?. Psicologia: Reflexão e Crítica.
Nagy, W., Berninger, V., \& Abbot, R. (2006). Contributions of morphology beyond phonology to literacy outcome of upper elementary and middle-school students. Journal of Educational Psychology, 98(1), 134-147.

Nunes, T. Bindman, M., \& Bryant, P. (1997). Morphological strategies: Developmental stages and processes. Developmental Psychology, 33(4), 637-649.

Nunes, T., \& Bryant, P. (2006). Improving literacy by teaching morphemes. London: Routledge.

Plaza, M., \& Cohen, H. (2004). Predictive influence of phonological processing, morphological/syntactic skill, and naming speed on spelling performance. Brain and Cognition, 55, 368-373.

Pinheiro, A. M. V. (1996). Contagem de freqüência de ocorrência de palavras expostas a crianças na faixa pré-escolar e séries iniciais do $1^{\circ}$ grau [Software]. Associação Brasileira de Dislexia - ABD.

Rego, L., \& Buarque, L. (1997). Consciência sintática, consciência fonológica e aquisição de regras ortográficas. Psicologia: Reflexão e Crítica, 10(2), 199-217.

Queiroga, B., Lins, M., \& Pereira, M. (2006). Conhecimento morfossintático e ortografia em crianças do ensino fundamental. Psicologia: Teoria e Pesquisa, 22(1), 95-99.

Stein, L. M. (1994). TDE - Teste de desempenho escolar: Manual para aplicação e interpretação. São Paulo: Casa do Psicólogo.

Sterling, C. (1991). Introduction to the psychology of spelling. Em C. Sterling, \& C. Robson (Orgs.). Psychology, spelling \& education. (pp. 1-15). Adelaide: Multilingual Matters.

Wechsler, D. (1991). WISC-III: Escala de inteligência Weschsler para crianças. São Paulo: Casa do Psicólogo.

Recebido: $28 / 02 / 2007$

Última revisão: 10/04/2008 Aceite final: $23 / 04 / 2008$

\section{APÊNDICE: TAREFAS DE CONSCIÊNCIA MORFOLÓGICA}

1) Decisão morfo-semântica (Besse, Vidigal de Paula \& Gombert, comunicação pessoal, setembro de 2005)

\section{Prefixo: Base-simples-derivada}

Descolorir-Deslizar-Destorcer; Desanimar-Despedir-Desobedecer; Desabafar-Destinar-Desatar; Desarmar-Despertar-Desconfiar; Desconhecer-Desafiar-Desrespeitar; Desatar-Desperdiçar-Descuidar; Reflorir-Recomendar-Reconhecer; Reaparecer-RecuperarReproduzir; Revender-Relatar-Reformar; Reabrir-Regar-Reler; Reescrever-Relacionar-Reflorestar; Replantar-Reservar-Relembrar

\section{Sufixo: Base-Simples-Derivada}

Chaveiro-Pandeiro-Cinzeiro; Galinheiro-Chiqueiro-Formigueiro; Passageiro-Escoteiro-Açougueiro; Jardineiro-Pioneiro-Guerreiro; Letreiro-Cheiro-Faqueiro; Bagageiro-Picadeiro-Banheiro; Corredor-Computador-Regador; Protetor-Autor-Inventor; Fedor-Furor-Frescor; Sucessor-Doutor-Pintor; Instrutor-Major-Feitor; Amargor-Vigor-Temor

2) Tarefa de decisão morfo-semântica - raiz

prefixo

Base-Derivada (en, re, des) - Simples 
Canta-Encantada-Enfeitada; Gole-Engole-Enxerga; Rola-Enrola-Enxuga; Cera-Encera-Encosta; Ler-Releia-Relata;

Tirar-Retira-Reserva; Tornar-Retorna-Resolve ; Aguar-Deságua-Deserta; Cansar-Descanso-Desmaio; Cobrir-Descobre-Desperta

sufixo

Base-Derivada (eiro, or, ada) - Simples

Pinho-Pandeiro-Pinheiro; Leite-Ligeira-Leiteira; Banho-Fevereiro-Banheiro; Canta-Motor-Cantor; Pinta-Tambor-Pintor;

Ler-Doutor-Leitor; Vale-Calor-Valor; Faca-Espada-Facada; Laço-Jangada-Laçada; Chave-Chiqueiro-Chaveiro

3) Tarefa de associação morfo-semântica (Nagy, Berninger \& Abbot, 2006).

pares não relacionados: chique-chiqueiro, panda-pandeiro, banda-bandeira, figa-fígado, calo-calor

pares relacionados: pedra-pedreiro, banho-banheiro, pinho-pinheiro, liga-ligado, escrita-escritor

4) Analogia gramatical (adaptado de Nunes, Bindman \& Bradley, 1997)

a) pedra-pedreiro; leite-? b) leitor-leu; escritor-? c) banana-bananada; goiaba-? d) pintor-pintura; livreiro-? e) livro-livraria; pão-? f) goma-engoma; gole-? g) tênis-tenista; arte-? h) lixo-lixeira; faca-? i) duque-duquesa; rei-? j) claro-clareza; belo-?

\section{Nota:}

Agradecemos às alunas de Iniciação Científica Luciana Annibal e Simone Lima pela participação na coleta de dados desta pesquisa.

\section{Sobre a autora:}

Márcia Maria Peruzzi Elia da Mota: Universidade Federal de Juiz de Fora, Programa de Pós-Graduação em Psicologia, Doutora em Psicologia pela Universidade de Oxford - Inglaterra.

Endereço para correspondência: Rua Coronel Vaz de Melo 49/202 - Bom Pastor - 36021-670 Juiz de Fora/MG - Endereço eletrônico: mmotapsi@terra.com.br. 